\title{
Management of A Paraglottic Synovialosarcoma: About A Case
}

Najoua Belhaj $^{1 *}$, Razika Bencheikh ${ }^{2}$, Ihsane Allouch ${ }^{1}$, Mohammed Anass Benbouzid ${ }^{2}$, Leila Essakalli ${ }^{2}$

${ }^{1}$ Resident Physician in Otorhinolaryngology, Department of Otorhinolaryngology, Head and Neck Surgery, Ibn Sina University Hospital, Faculty of Medicine, Mohammed V University, Rabat, Morocco

${ }^{2}$ Professor of Otorhinolaryngology, Department of Otorhinolaryngology, Head and Neck Surgery, Ibn Sina University Hospital, Faculty of Medicine, Mohammed V University, Rabat, Morocco

DOI: $10.36348 /$ sjmps.2020.v06i10.001

| Received: 18.08.2020 | Accepted: 25.08.2020 | Published: 05.10.2020

*Corresponding author: Belhaj Najoua

\section{Abstract}

Cervicofacial synovialosarcoma is a malignant tumor. It poses a diagnostic and therapeutic problem. Synovialosarcoma has the strongest recurrence power among soft tissue sarcomas. These recurrences are more frequent during the first two years. Distant metastases are seen in $30 \%$ to $50 \%$ of cases and are mainly pulmonary. We report the observation of a young 38-year-old patient who was operated on in 2013 for synovialosarcoma oropharynx with radiotherapy postoperatively 6 years after the patient has two recurrences, one oropharyngeal and the other cervical.

Keywords: Paraglottic Synovialosarcoma Cervicofacial tumor.

Copyright @ 2020: This is an open-access article distributed under the terms of the Creative Commons Attribution license which permits unrestricted use, distribution, and reproduction in any medium for non-commercial use (NonCommercial, or CC-BY-NC) provided the original author and source are credited.

\section{INTRODUCTION}

Synovialosarcoma is a rare malignant mesenchymal tumor, representing $5 \%$ to $10 \%$ of soft tissue sarcomas [1]. It mainly affects adolescents and young adults, with preferential limb damage [2]. Localization in the ENT sphere is very rare, representing less than $5 \%$ of tumors in this region [3] and essentially located at the level of the hypopharynx and the para-pharyngeal space. Standard treatment is based on broad and complete excision, alone or combined with post-operative external radiotherapy.The prognosis is generally poor due to local recurrences which are observed in $8 \%$ to $60 \%$ of cases[4]. Synovialosarcoma has the strongest recurrence power among soft tissue sarcomas. These recurrences are more frequent during the first two years. Distant metastases are seen in $30 \%$ to $50 \%$ of cases and are mainly pulmonary [2, 4, 5]. In this work, we report the observation of a young 38-year-old patient who was operated on in 2013 for synovialosarcoma oropharynx with radiotherapy postoperatively 6 years after the patient has two recurrences, one oropharyngeal and the other cervical.

\section{Case Report}

This is a 38-year-old patient, with no notable pathological history, who presented a year before her first consultation with a left earache associated with odynophagia. The clinical and fibroscopic examination revealed a budding lesion in the posterior wall of the oropharynx without associated cervical adenomegaly. The extension assessment including cervical magnetic resonance imaging (MRI) objectified a heterogeneous tissue lesion process of $6 \mathrm{~cm}$ at the level of the posterior wall of the oropharynx, extended below the hypopharynx, with iso signal in $\mathrm{T} 1$ compared to muscle, and hyposignal in T2, without associated cervical lymphadenopathy. A chest CT scan as part of the remote extension checkup was normal. A monoblock resection of the tumor without lymph node dissection was performed. The anatomopathological study of the operating room has objectified a fusocellular mesenchymal proliferation whose appearance was in favor of sarcoma. The immunohistochemical complement revealed a positive labeling of tumor cells with cytokeratin, EMA, vimentin and PS 100, with an absence of labeling with AML CD34 and Desmine. The FNCLCC grade II synovialosarcoma diagnosis was accepted. The patient received adjuvant radiotherapy at a dose of $70 \mathrm{~Gy}$, the patient was monitored clinically and by cervicothoraco-abdomino-pelvic CT imaging.

6 years later, the patient has a left laterocervical mass, for which she underwent a cervicotomy under general anesthesia. The result of which was an extemporaneous study and definitive anapath came back in favor of synovialosarcoma in a second cervical localization limit's excision were healthy, for this second cervical localization no 
radiotherapy. 7 months after the patient presented odynophagia with installation of dysphagia with solids of progressive installation, the clinical examination did not find a palpable cervical mass, oropharyngeal examination objectified a tissue mass hidden by the base of the tongue. The patient benefited from an injected cervical scanner which returned in favor of a process on the glottis subglottic stage in posterior extending from the first cervical vertebra to seven cervical vertebra, increasing after injection of contrast agent measuring $37 * 39 * 62 \mathrm{~mm}$ without mass effect on the jugulocarotid axis (Figure 1).

The assessment completed by a direct laryngoscopy and a hypopharyngoscopy with general anesthesia which showed a tissue lesion at the expense of the left aryepiglottic fold not invading the glottic plane nor the sub glottic plane, the base of the tongue and the valecules were healthy .Hypopharyngoscopy could not find involvement of the two piriform sinuses or the oesosphageal mouth, a biopsy made addressed to the pathology study returning in favor of synovialosarcoma.

The patient had an endoscopicaly excision of the whole tumor, then extemporaneous pathologic examenination confirmed the diagnosis of synovialosarcoma. Then we did a cervical approach on the old incision of (2013) .We did not find any tumor.So It was not a recurrence but a new localisation of paraglottic synovialosarcoma.

There where no post operative complication. The patient was referred to medical oncology for a chemotherapy according to the protocol based on DOXORUBICINE and ISOFOSFAMIDE: DOXORUBICINE $75 \mathrm{mg} / \mathrm{m} 2$ per day for 5 days and isofosafamide $1.8 \mathrm{mg} / \mathrm{m} 2$ per day for 5 days, the same protocol repeated on day 21 .

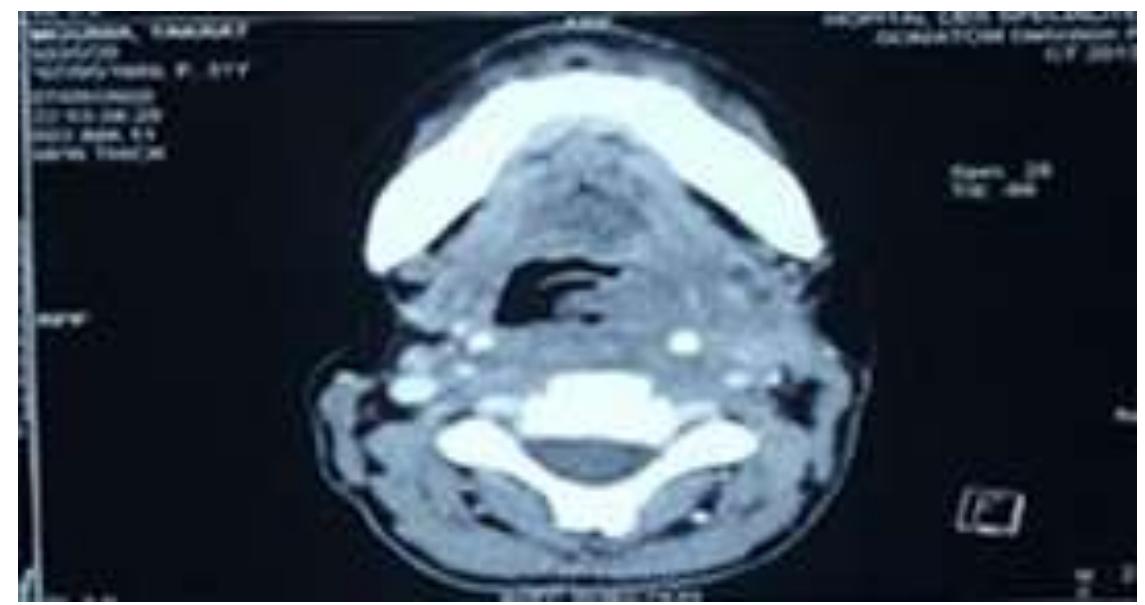

Fig-1: Axial sections of the cervico-thoracic scanner carried out in 2020 for the last oropharyngeal recurrence showed the paraglottic extension

\section{DISCUSSION}

Synovialosarcoma is a rare, high-grade tumor of connective tissue malignancy, often occurring next to the joints. This tumor does not originate from synovial tissue, but rather from pluripotent mesenchymal cells near or even away from joint surfaces [6, 9]. Synovialosarcoma mainly affects the lower limbs. Cervico-facial localization is rare. She sees herself in less than $10 \%$ [9].

According to literature reviews, almost 100 cases have been reported [6,9]. The most common locations are the pharynx, parapharyngeal space and the joints between the cervical vertebrae [6]. Laterocervical localization is only reported by a few publications. Classically, synovialosarcoma is seen in young people. It occurs in $90 \%$ of cases before the age of $50[7,9]$.

Some infantile forms have been described [10]. The tumor mainly affects humans [9].
Synovialosarcoma most often presents after a lag time of 1 to 2 years in the form of a soft mass, slowly increasing in size often simulating a benign process [11].

Pain is often present and may be the only functional sign, due to the invasion or compression of adjacent structures. Signs of sensory and / or motor dysfunction are rarer. The imagery is not specific. Usually synovial sarcomas manifest as well-defined solid masses on CT or MRI scans [9-11].

Infiltration of adjacent soft tissue is a less common finding. The lesions can be homogeneous or heterogeneous, depending on the degree of hemorrhage or necrosis. The contrast enhancement is variable but it is often moderate. About $30 \%$ of synovialosarcomas contain calcifications which may be apparent on CT [4, 5]. The presence of calcifications is correlated with a good prognosis. In our case, there were no calcifications on the imagery [11]. 
The treatment of choice is complete excision with wide margins, but it is rarely feasible at the cervico-facial level [12]. Lymph node involvement is exceptional. Therefore, lymph node dissection is not recommended in the absence of lymphadenopathy [13]. The synovial sarcoma of the head and neck has an aggressive character and a poor prognosis. Several factors were assessed for prognosis, the most important of which were tumor size and deep extension at the time of primary treatment, with survival varying inversely with these two factors [14-16].

Most authors indicate adjuvant radiotherapy for better locoregional control. The value of chemotherapy is not yet well defined [11, 13]. Its efficacy on soft tissue sarcomas has not yet been demonstrated, but some tumors have significant sensitivities, it is usual in high grade soft tissue sarcomas of malignancy in addition to surgery. There is no standard neoadjuvant chemotherapy protocol in STM. Since the main objective in this situation is the response rate, preference should be given to multidrug therapy protocols (doxorubicin combination + ifosfamide), The optimal dose is $75 \mathrm{mg} / \mathrm{m} 2$. Other molecules are also effective but to a lesser degree: dacarbazine, cyclophosphamide, cysplatin, antracycline and epirubicin.

Many association protocols have been proposed, the cytotoxic molecules of choice are those giving the best response rate. Either protocol: doxorubicin + isofosfamide o Either protocol: doxorubicin + isofosfamide + dacarbazine [16].

The use of systematic adjuvant chemotherapy remains controversial in the treatment of adult STM, indeed the studies are contradictory. It does not represent a standard. If there is evidence that adjuvant chemotherapy improves survival without local relapse and relapse without metastasis, its impact on overall survival has not been demonstrated. This approach can be offered to selected patients at high risk (grade 2-3,> $5 \mathrm{~cm}$ ). If adjuvant chemotherapy: use of a combination comprising doxorubicin and ifosfamide in optimal doses (4 to 6 cycles) [17-23].

For palliative chemotherapy: It is intended for metastatic patients for whom a curative program cannot be offered. The standard chemotherapies continue today to use doxorubicin and ifosfamide. The response rates obtained with doxorubicin at the $75 \mathrm{mg} / \mathrm{m} 2$ dose as "monotherapy" vary from 8 to $30 \%$ depending on the study; they seem lower in the most recent studies, however most centers report a standard response rate of around $20 \%$ in current practice. Ifosfamide gives response rates of 6 to $15 \%$ with doses varying according to studies from 5 to $14 \mathrm{~g} / \mathrm{m} 2$, as has also been described with doxorubicin above $60 \mathrm{mg} / \mathrm{m} 2$, a dose effect seems likely for ifosfamide, response rates appear to be higher for doses greater than 9-10 g / m2. Large doses of ifosfamide are however burdened with severe toxicity, particularly haematological, but also digestive and sometimes renal, even neurological. If the combination of these two agents gives response rates of the order of $50 \%$ in many trials and therefore constitutes in many countries a standard treatment with, moreover, multiple variants - there is no To date, no randomized trial showing indisputably that multidrug therapy allows a significant increase in survival with a median survival time which peaks in all trials, around 10 to 12 months.

The current trend is therefore to reserve the DOXORUBICINE - IFOSFAMIDE combination for subjects in whom an increased response rate can translate into a real benefit, for example in the case of isolated potentially resectable pulmonary metastases or in the case of symptomatic diseases for which a few additional percentages of tumor regression can change the patient's daily life. This type of combination must also be proposed with a view to primary chemotherapy, because the tumor response conditions the surgical possibilities for patients with limited operability, but neoadjuvant chemotherapy should ideally be practiced in clinical trials. Several chemotherapies have been compared to DOXORUBICINE, including other anthracyclines [16, 21].

The development of a new targeted therapy is based on the identification of a target, specific for a subgroup of tumors and involved in the phenomena of carcinogenesis and / or tumor growth. Several studies have already shown the effectiveness of certain targeted therapies in STM.

The search for agents targeted against a tumor begins by assessing the "signature" of the tumor, its uniqueness. In sarcomas with known characteristic cytogenetic abnormalities, one begins by determining the character and the translocation or fusion protein function.

Synovialosarcomas have a characteristic translocation of chromosome 18 and $\mathrm{X}$, with one of the two variants of the SSX portion observed in more than $90 \%$ of cases. Suppression of the SYT-SSX protein or interference with its downstream targets could selectively inhibit the growth of synovialosarcoma cells. Unfortunately, there are unanswered questions about the biology of the fusion product, therefore targeted therapy steps remain to be studied.

\section{Conclusion}

Cervicofacial synovialosarcoma is a malignant tumor. It poses diagnostic and therapeutic problems. The prognosis is generally poor due to local recurrences which are observed in $8 \%$ to $60 \%$ of cases [4]. Synovialosarcoma has the strongest recurrence power 
among soft tissue sarcomas (STM). These recurrences are more frequent during the first two years. In our case, the recurrence was very rapid. Distant metastases are seen in $30 \%$ to $50 \%$ of cases and are mainly pulmonary, hence the need for close monitoring.

\section{REFERENCES}

1. Krieg, A. H., Hefti, F., Speth, B. M., Jundt, G., Guillou, L., Exner, U. G., ... \& Kaelin, A. (2011). Synovial sarcomas usually metastasize after> 5 years: a multicenter retrospective analysis with minimum follow-up of 10 years for survivors. Annals of oncology, 22(2), 458-467.

2. Park, J. K., Ham, S. Y., Hwang, J. C., Jeong, Y. K., Lee, J. H., Yang, S. O., ... \& Choi, D. H. (2004). Synovial sarcoma of the head and neck: a case of predominantly cystic mass. American journal of neuroradiology, 25(6), 1103-1105.

3. Rigante, M., Visocchi, M., Petrone, G., Mulè, A., $\&$ Bussu, F. (2011). Synovial sarcoma of the parotid gland: a case report and review of the literature. Acta Otorhinolaryngologica Italica, 31(1), 43.

4. Colville, R. J., Charlton, F., Kelly, C. G., Nicoll, J. J., \& McLean, N. R. (2005). Multidisciplinary management of head and neck sarcomas. Head \& Neck: Journal for the Sciences and Specialties of the Head and Neck, 27(9), 814-824.

5. Kouhen, F., Afif, M., Benhmidou, N., \& Rais, F. (2015). Le synovialosarcome de la sphère otorhino-laryngée: une localisation rare: à propos de deux cas. The Pan African Medical Journal, 20.

6. Bertolini, F., Bianchi, B., Pizzigallo, A., Tullio, A., \& Sesenna, E. (2003). Synovial cell sarcoma of the neck. Case report and review of the literature. Acta otorhinolaryngologica italica, 23(5), 391-395.

7. Blankenburg, S., Petersen, I., Katenkamp, D., \& Chilla, R. (2011). An unusual case of a synovial sarcoma of the parotid gland in an elderly patient. Auris Nasus Larynx, 38(4), 523-527.

8. Jernstrom, P. (1954). Synovial sarcoma of the pharynx: report of a case. American Journal of Clinical Pathology, 24(8), 957-961.

9. Ishiki, H., Miyajima, C., Nakao, K., Asakage, T., Sugasawa, M., \& Motoi, T. (2009). Synovial sarcoma of the head and neck: rare case of cervical metastasis. Head \& Neck: Journal for the Sciences and Specialties of the Head and Neck, 31(1), 131135.

10. Kallel, S., Mnejja, M., Ghorbel, L., Kallel, R., Charfeddine, I., Hammami, B., \& Ghorbel, A. (2013). Synovialosarcome cervical: a propos d'un cas. Journal Tunisien d'ORL et de Chirurgie Cervico-Faciale, 30, 67-69.

11. Kallel, S., Mnejja, M., Ghorbel, L., Kallel, R., Charfeddine, I., Hammami, B., \& Ghorbel, A. (2013). Synovialosarcome cervical: a propos d'un cas. Journal Tunisien d'ORL et de Chirurgie Cervico-Faciale, 30, 67-69.
12. Kartha, S. S., \& Bumpous, J. M. (2002). Synovial cell sarcoma: diagnosis, treatment, and outcomes. The Laryngoscope, 112(11), 1979-1982.

13. Giaoui, L., Salvan, D., Casiraghi, O., Mamelle, G., \& Julieron, M. (1999). Synovialosarcomes cervicofaciaux: Expérience de l'Institut Gustave Roussy. A propos de 13 cas. In Annales d'oto-laryngologie et de chirurgie cervico-faciale (Vol. 116, No. 2, pp. 71-77).

14. Bukachevsky, R.P., Pincus, R.L., Shechtman, F.G., Sarti, E., Chodosh, P. (1992). Sarcome synovial de la tête et du cou. Head Neck, 14(1): 44 -48

15. Carrillo, R., Rodriguez-Peralto, J.L., Batsakis, J.G. (1992). Sarcome synovial de la tête et du cou. Ann Otol Rhinol Laryngol, 101(4): 367-370

16. Italiano, A., Penel, N., Robin, Y.M., (2009). La chimiothérapie néo / adjuvante n'améliore pas les résultats du sarcome synovial primaire réséqué: une étude du groupe français des sarcomes. Ann Oncol, 20(3): 425-430

17. Sarcoma Meta-analysis Collaboration. (1997). Adjuvant chemotherapy for localised resectable soft-tissue sarcoma of adults: meta-analysis of individual data. The Lancet, 350(9092), 1647-1654.

18. Brodowicz, T., Schwameis, E., Widder, J., Amann, G., Wiltschke, C., Dominkus, M., ... \& Zielinski, C. C. (2000). Intensified adjuvant IFADIC chemotherapy for adult soft tissue sarcoma: a prospective randomized feasibility trial. Sarcoma, 4.

19. Frustaci, S., Gherlinzoni, F., De Paoli, A., Bonetti, M., Azzarelli, A., Comandone, A., ... \& Apice, G. (2001). Adjuvant chemotherapy for adult soft tissue sarcomas of the extremities and girdles: results of the Italian randomized cooperative trial. Journal of clinical oncology, 19(5), 12381247.

20. Petrioli, R., Coratti, A., Correale, P., D’Aniello, C., Grimaldi, L., Tanzini, G., ... \& Pirtoli, L. (2002). Adjuvant epirubicin with or without ifosfamide for adult soft-tissue sarcoma. American journal of clinical oncology, 25(5), 468-473.

21. Woll, P. J., Van Glabbeke, M., Hohenberger, P., Le Cesne, A., Gronchi, A., Hoekstra, H. J., ... \& EORTC Soft Tissue \& Bone Sarcoma Group. (2007). Adjuvant chemotherapy (CT) with doxorubicin and ifosfamide in resected soft tissue sarcoma (STS): interim analysis of a randomised phase III trial. Journal of clinical oncology, 25(18_suppl), 10008-10008.

22. Pervaiz, N., Colterjohn, N., Farrokhyar, F., Tozer, R., Figueredo, A., \& Ghert, M. (2008). A systematic meta- analysis of randomized controlled trials of adjuvant chemotherapy for localized resectable soft- tissue sarcoma. Cancer: Interdisciplinary International Journal of the American Cancer Society, 113(3), 573-581.

23. Pervaiz, N., Colterjohn, N., Farrokhyar, F., Tozer, R., Figueredo, A., \& Ghert, M. (2008). A 
systematic meta- analysis of randomized controlled trials of adjuvant chemotherapy for localized resectable soft- tissue sarcoma. Cancer: Interdisciplinary International Journal of the American Cancer Society, 113(3), 573-581.

24. Albritton, K. H., \& Randall, R. L. (2005). Prospects for targeted therapy of synovial sarcoma. Journal of pediatric hematology/oncology, 27(4), 219-222.

25. Annals of Oncology. (2010). Published online 17 August 2010. Synovial sarcomas usually metastasize after $>5$ years: A multicenter retrospective analysis with minimum follow-up of 10 years for survivors. 22: 458-467, 2011.doi:10.1093/annonc/mdq394

26. Les sarcomes des tissus mous: Aspects epidemiologiques, cliniques et therapeutiques. Expérience de l'Hôpital Militaire Moulay Ismail de Meknès. (A PROPOS DE 18 CAS) Thèse $\mathrm{N}^{\circ}$ $108 / 19$. 